\title{
Responsible environmental attitudes as recipe for sustainable environment in Nigeria
}

\author{
Abiodun A. Oladiti, Binta T. Kamarise \\ Department of Social Studies, School of Arts and Social Sciences, \\ Emmanuel Alayande College of Education, Oyo, Oyo State, Nigeria
}

\begin{abstract}
Environmental sustainability is currently a topical issue globally. Reason for this might not be unconnected with the need to ensure balancing of environmental protection as well as social responsibility as requisite for healthy environment and economy. Thus, an understanding of the indispensability of environment generally has led to the clarion call for better steward of environment by human beings, bearing in mind the deteriorating state of the environment and its consequences. This study employed a triangulation of instrument in developing responsible attitude towards environment. 72 participants involving artisans, technocrats, farmers, marketers, industrialists, public servants and institutions were drawn across urban and peri-urban areas within four local governments in Oyo, Oyo state, Nigeria. In-depth interviews were conducted among the participants on the extent, effects of human impacts as well as desirability of responsible attitudes to the environment. Data were analyzed through coded description, verbatim reporting, content analysis and categorization of ideas expressed by participants in the IDIs. It was revealed that human beings have impacted on the environment in a number of ways culminating in untold effects on the environment and its components. The need for responsible attitude to environment was therefore suggested as measure towards sustainable environment and development.
\end{abstract}

Keywords: Environment; Human impact; Responsible attitude; Sustainable environment

\section{INTRODUCTION}

It is never an overstatement to say that more than any other factor, the continuous existence and survival of the world population hinges on sustainable environment. Globally the population has since been experiencing astronomical growth. From the year 2003 figure put at 6.1 billion, the world population has reached $6,7,8,107,712$, a figure that has doubled that of 1960 since for every human that dies daily, two are given birth to especially among the underdeveloped nations (Meyer, 2003; Raymond, 2012). The said growth in population is not without attendant effects on the environment generally. For instance, Kevin and Lewis (1995) advanced that with the rapid growth of the world's population, many societies have been demanding more from the earth's resources and affecting its land surface at ever increasing rates. Similarly, Oladiti (2007) attributed the inadequacy of the carrying capacity of the environment nowadays to the continuous growth in the world population.

In like manner, the nature of the environmental resources as a component of the environment also attest to the seemingly inability of its carrying capacity. Reason for this 
might not be unconnected with the fact that while some resources are renewable, a good number of them are non-renewable. Thus, such resources, due to human's actions and inactions are already tending towards extinction. This is also a product of too many human wanting too much whether it is food, land, power or influence (Kelvin \& Lewis 1995). It therefore calls for caution on the part of human beings not to jeopardize the source of survival both for now and the future as captured in the old Indian saying - 'the earth is not a heritage given to us by our ancestors but loaned to preserve it for our offspring'. Also, some renewable resources are being used at rates exceeding their regenerating speed.

The foregoing perhaps is an attestation of the timely nature of this conference and its theme 'our changing environment' as an educative measure towards imputing sanctity in human environmental attitude. In apparent attestation of the proclivity of education in procuring solutions to human problems, environment inclusive, Akinkuotu (2012) asserted that the quality of education will go a long way in shaping the nation, individual and collective future in Nigeria. It is described as an imperishable asset for the country (Oladiti \& Wahab 2013). Furthermore, the place of education in sustainable environment in particular and sustainable development in general has been recognized. For instance, Gbadamosi (2012) quoting UNESCO advanced that:

Education for sustainable development described in chapter 36 of agenda 21 stated that education, including formal education, public awareness and training should be recognized as a process by which human beings and societies can reach their fullest potential. Education is critical for promoting sustainable development and improving the capacity of people to address environment and development issues. Both formal and non-formal education is indispensable to changing people's attitudes so that they have the capacity to assess and address their sustainable development concern (p. 56).

If the assertions of UNESCO (2008) and that of Gbadamosi (2012) that education is the most effective means that society possess for confronting the challenges of the future and capable of shaping the world of tomorrow is anything to go by, then it is imperative to develop responsible environmental attitude in the populace which is the crux of this paper.

\section{THE STUDY}

The challenges posed by environmental problems both in the past and in the present time have led to a number of efforts at curtailing the phenomenon. Thus, successive governments in Nigeria have at one time or the other come up with policies aimed at addressing the issue. Government at various levels coupled with NGO as well as organizations and individuals have made frantic efforts at salvaging the environment from deleterious human impacts. Many of such efforts are in consonance with the international stance on environment such as international workshop and conferences. The foregoing stances notwithstanding however, the state of environment currently is devastating with untold effects of climate change impacting on the entire ecosystem and human society with all impunity. Thus, the whole world is currently experiencing devastating weather hazards and associated disrupted seasonal cycles. All these are affecting the ecosystem, agriculture, water sheds, food production, sea level rise, floods, hurricanes, drought and to mention few. The foregoing is but product of human action and inactions on the cosmos generally which according to MINET (2012), will create overwhelming problems for an already impoverished populace. 
The corollary of the foregoing is the clarion call for attitudinal change to environment to engender sustainable environment and development altogether. This paper therefore examined the place of responsible environmental attitudes in the promotion of sustainable environment.

In specific term, the study examined the concept of environment and sustainable environment, theories relating to man-environment interaction, man's dependency on the environment, situational analysis of environment vis-avis human impact on environment as well as the need for responsible environmental attitude. The study was conducted as a survey study among 72 participants drawn across four local governments in Oyo township of Oyo state through accidental sampling technique among artisans, technocrats, farmers, marketers, industrialists, public servants and institutions. Being a qualitative study, in-depth interviews (IDIs) were conducted among the participants within a period of two weeks in April 2014. Tape recordings of the interviews were played back and transcribed coupled with notes taken on the field and utilized in the report for the study. Data were analyzed through content analysis, verbatim reporting, code description and categorization of views expressed by participants in to divergent and convergent views. The study was anchored on thoughtprovoking issues bothering on the extent of human impact on the environment, effect of human attitude on the environment as well as the impact of responsible environmental attitude on sustainable environment.

\section{THEORETICAL FRAMEWORK}

This work is premised on two theories, first, the environmental determinism and environmental possibilism theory as put up by Nwankiti (1983). The second theory is the Moral Foundations theory. The theories of environmental determinism and environmental possibilism have been adopted in explaining the reciprocal relationship between man and the environment. Environmental determinism implies the impact or environment on man in terms of influence being exerted on man by the environment. Thus, environmental determinism holds that man will always carry out certain activities such as occupation, religion, shelter, culture, economic activities according to the dictate of the environment, thus, man has to dance to the tune of environment. On the contrary, environmental possibilism is a reaction to the postulates of environmental determinism. It postulates that man is not a slave to his environment hence, as environment influences man, to a greater extent, man in his quest to satisfy his numerous needs do adapt, modify and bring environment under control. Thus, environmental possibilism is a description of man's impact on the environment toward making possible the impossibilities of the environment through developed science and technology. Man therefore is a possibilistic animal. The foregoing does shape human environmental impacts at large.

Moral foundations theory expressly presents moral suasion and environmental attitudes (Feinberg \& Willer, 2012). The theory discusses the ever increasing polarization on environmental issues whereby 'the liberals' position themselves as guardians of the environment while 'the conservatives' generally opposes reforms meant for environmental protection (Dunlap, Xiao \& Mcright, 2011, Feygina, Jost \& Goldsmith, 2010; Mc Right \& Dunlap, 2011). Reason for the polarization according to Feinberg and Willer (2012) is the different perception of environmental concern as a moral issue. The strength of moral concerns over individual's attitudes and behaviour has been recognized (Chen, Pillutla \&Yao, 2009; Lakoff, 1996). Also, with regards to environmental attitudes, studies such as Stern, Dietz, Abel, Guagnano and Kalof (1999) adduced that there is correlation between moral 
perception of environmental issues and individual's environmental attitudes. This notion has its root in Schwarts (1977) norm-activation model which says that the more individuals recognizes the consequences of environmental degradation, the more they feel personally responsible for such degradation, the more they view pro-environmental behaviour as moral. The import of this theory is in effect, human dispositions to the environment generally.

\section{ENVIRONMENT AND SUSTAINABLE ENVIRONMENT}

Environment as a concept connote the surrounding phenomenon of the planet earth. It has its origin in the French word 'environ' which literarily translate to surrounding. Environment therefore constitutes the single complex whole that contains everything that makes up the world. It entails arts and crafts, flora and fauna, traditions and history, weather and climate, rivers, lakes and vegetation (Oladiti, 2010). By implication, environment contains everything that human life hinges on. Thus, in the context of human development, environment is seen as the totality of the objects and conditions surrounding human existence. Arising from the foregoing, guarding jealously the environment becomes pertinent. This calls for rational use of the environmental resources in the present time, bearing in mind the future generation. Hence, sustainable environment entail increased ecological awareness and promotion of healthy environment. This perhaps is the idea behind the old Indian saying, the earth is not a heritage given to us by our ancestors but loaned to preserve it for our offspring. Presenting an illuminating stance on sustainable environment, Benedict (2005) was of the view that it entails increased ecological awareness and promotion of healthy environment. This is in consonance with the $7^{\text {th }}$ goal of agenda 21 of MDGs focusing on ensuring environmental sustainability with a view to integrating the principles of sustainable development with country policies and programmes capable of reversing the loss of environmental resources.

Attributing the task of ensuring sustainable environment to human beings, Kevin and Lewis (1995) contended that human, unlike other animals have the ability, if not always matched by the foresight to appreciate the responsibility for managing the planet wisely and the capacity to control human actions and monitor their impact on the environment, this translates to sustainable environment. Little wonder the assertion that for the foreseeable future, sustainable management of the environment will be of greatest challenges confronting the world. Reasons for this might not be unconnected with the fact that climate change, loss of plants and animals, biodiversity, declining fisheries and trade in endangered plants and animals, disrupted seasonal cycles, rise in sea levels and its concomitant effects are but tip of the iceberg in terms of environmental threats affecting the word (Environmental Education Training Manual, 2007; Gbadamosi, 2012; Ogundare, 2013). By implication, environmental sustainability underscores decision making and action taking in the interests of protecting the natural world. The major emphasis of such action therefore is on preservation of the capability of the environment to support human life. This has been expressly captured in the views of Kevin and Lewies (1995) that the greatest challenges confronting society and government of today and the generations to come is the sustained development and intelligent management of the planet. As such, environmental sustainability is driven by responsive attitude as encapsulated in the position of Technology for a Sustainable Environment (TSE, n.d) viz:

Environmental sustainability forces business to look beyond making short term gains and look at the long impact they are having on the natural world. You need to consider not only the immediate impacts your actions have on 
the environment, but the long term implications as well. For example, when manufacturing a product, you need to look at the environmental impact of the products' entire life cycle, from development to disposal (p. 6).

An integration of such attitude in individuals and other stake holders on the environment is a key to sustainable environment and sustainable development at large.

\section{DEPENDENCY ON THE ENVIRONMENT}

The existence and continuous survival of human being is embedded in the environment. Little wonder the saying, no environment, no man, corollary of which is man's dependence on the cosmos. Reiterating the symbiotic relationship between human being and environment, Oladiti (2010) advanced that all the essential things of life, food, water, air, shelter, heat, light and other life supporting elements are obtained from the environment. Attesting to the foregoing, Gbadamosi (2012) adduced that the quality of life is measured in the basic needs. The said basic needs which are products of the environment are the air we breathe, the water we drink as well as the food we eat.

The extent of dependency on the environment could be inferred from the submissions of Kevin and Lewies (1995) that in more recent times, human beings have destroyed enormous tracts of natural vegetation; excavated large areas of land, greatly modified the landscape and even created new land. Buttressing this fact, Adekunle (2005) indicated that the current rates of growth in population, industrial production consumerism and environmental degradation cannot be supported indefinitely by earth's finite carrying capacity. Furthermore, TSE (n.d) indentified some common environmental concern showcasing level of dependency of human on environment. Such concerns are: damaging of rainforests and wood lands through logging and agricultural clearing; polluting and over-fishing of oceans, rivers and lake, pollution of the atmosphere through the burning of fossil fuels and, damaging of prime agricultural and cultivated land through the use of unsustainable farming practices. Without mincing words, afore-mentioned are carried out all in a bid to satisfy the ever increasing teaming population's basic needs generally. This thus account for the situation of environment presently.

\section{HUMAN ENVIRONMENTAL IMPACT AND RESPONSIBLE ENVIRONMENTAL ATTITUDE}

As a possibilistic animal, human beings in a bid to satisfy their ever increasing needs tend to tamper with the environment. Thus, in the quest to satisfy one need, human beings keep on exploring and exploiting environmental resources which in most cases are associated with concomitant effects. Summing up human environmental impact, Jekayinoluwa(2005) advanced that the plant and the global environment are witnessing most profound changes in the brief history of the human specifics. Changes such as depletion of stratospheric ozone, threat of global warming, deforestation, acid precipitation, extinction of species and numerous others are bye-product of human activities on the environment.

Four main components of the ecosphere that are potentially under threat from human activities have been identified by Kevin and Lewies (1995). These are: climatic system in terms of destruction of the ozone layer, emission of gases into the atmosphere. This is followed by global circulation of nutrients, threatening of the hydrological cycle through pollution, droughts and floods and the reduction of biological diversity and changes in the 
vegetation character of various regions of the world. The foregoing constitutes the basis of categorization of human impact on the environment in to soil, landscape and urbanization. The same have been construed by Ogundare (2013) as responsible for climate change which was delineated into three headings of electrical pollution and associated fossil fuels burning, garbage and resultant landfills, burning of which culminate in green house gasses and the illicit cutting of trees.

In like manner, the impacts of human beings on the environment have been identified as responsible for two interrelated problems of pollution and resource depletion. Thus, the global natural environment is now in certain critical dimension which thus, limits its carrying capacity. The said situation is a product of either sheer ignorance of such impact or wrong headed discounting of the need for judicious use of the resources (Agunbiade, 2007; Gbadamosi, 2012).

Literature is replete of various human environmental impacts. This perhaps informed the submission of TSE (n.d) that environmental sustainability currently is a topical issue receiving plenty of attention from the media from different governmental departments, a product of on-going research in assessing impact of human activity on environment. The grouping of Nigeria among the countries of the world with relatively low peace coupled with the country's ranking of $146^{\text {th }}$ out of 153 countries and being grouped among the 32 countries marked with red (Oladiti \& Wahab,2013; Mordi, 2012) is not without adverse effects on the environment that used to be at the receiving end.

Furthermore, the actions and inactions of human beings on the environment are already making the environment inhabitable for living and non-living organisms. For instance, the National Mirrow in its Tuesday April 1, 2014 edition gave a stunning report on the state of air worldwide resulting from pollution. The paper quoting recent report credited to World Health Organization (WHO) affirmed that outdoor air pollution ranks among the top 10 killers on earth with the death toll rising from an estimated 2.4 million lives in 2010 to over seven million people killed in 2012. Berating attitudes of Nigerians to environmental issue, the newspaper adduced that Nigerians remain at risk of endangering its citizens due to lax attitude to enforce the law that are capable of curtailing the emission of poisonous substance being inhaled daily via indiscriminate deposit into the air.

In the same vein, the Minister of Environment, Mrs Laurencia Mallam has alerted the nation on the increasing spate of desertification in the country. Presently, it is revealed that over $35 \%$ of the nation's land mass is being threatened by desert encroachment. The scenario is definitely of grave consequence on both inhabitants and the general ecology. Little wonder the conclusion of the minister that incessant communal clashes that engulfed the nation are of concomitant negative impacts on the lives and property of the people. Also, the National Emergency Management Agency (NEMA) recently disclosed that no fewer than 5,000 people have been displaced by wind storms in Osun, Oyo and Ekitit states in the past three months. To this end, the NEMA zonal coordinator, Alhaji Iyiola Akandemade urged Nigerians to embark on voluntary tree planting as preventive measure against effects of climate change in the contemporary world. The said clarion call is a call for responsible attitude towards the environment. Reason for this stance might not be unconnected with the expectations from human beings in ensuring sustainable environment. This position buttresses the submission of Adedoyin (2014) that people are the key to management of both natural and man-induced disasters in order to reduce incidence of fatalities and loss of properties, environmental resources inclusive.

At this junction, the imperativeness of responsible attitude to the evolving environment is obvious. The continuous battering of the environment is affecting the entire system, 
corollary of which is life threatening and endangering of species, human and other organism alike. Since human livelihood is a function of healthy environment, it therefore calls for development of concern and commitment among the people. More so, the future of mankind in the face of the perennial environmental problems can only be guaranteed through environmental consideration in human endeavours, corollary of which is individual attitudes as the basis of responsible environmental attitude (Benedict, 2005; Ajiboye \& Oyetade, 2005; Adekunle, 2006).

\section{FINDINGS AND DISCUSSIONS} study.

This section focuses on the descriptive and qualitative analysis of data collected on the

Table 1. Descriptive Analysis of Participants' Demographic Data.

Age
$25-35$
$15(20.83 \%)$
36-55
$26(36.11 \%)$
$56-65$
$18(25 \%)$
66 and above
$13(18.06 \&)$

Sex

$\begin{array}{ll}\text { Male } & 28(38.89 \%) \\ \text { Female } & 44(61.11 \%)\end{array}$

Location

Urban

Peri-Urban
$42(58.33 \%)$

$30(41.67 \%)$
Occupation/Profession

Artisans (skill workers)

Technocrats (technical experts)

Farmers

Marketers

Industrialists

Public Servants
Male

08

07

06

04

05

05
Female Total

02

01

08

04

10

04

08

04

09

05 


$\begin{array}{llcl}\text { Institutions } & 04 & 03 & 07 \\ \text { Others } & 05 & 05 & 10 \\ & 44 & 28 & 72\end{array}$

Total

72

Source: Authors' Fieldwork 2014

The demographic data of participants presented in Table 1 indicated that $44(61.11 \%)$ out of the 72 participants were male while 28 (38.89\%) were female. Most of the participants were from urban areas $42(58.33 \%)$ and majority of them belonged to the working population with age range of 36-65 years. Participants cut across different strata of the society.

In analyzing the data collected on the extent of human environmental impact, coded descriptions of participants' views have been attempted. Specially, the participants' perceptions of the extent of human impacts on the environment were coded into five broad categories. These are: (a) vegetation manifesting in illicit bush-burning, lumbering, overgrazing, deforestation and desertification; (b) soils inform of erosion, pollution, chemical changes, irrigation, flooding, etc; (C) oceans, sea, and rivers manifesting in pollution, coastal reclamation, dredging, over-exploration and exploitation of water resources, deposits, etc; (d) landscape in areas of landfills, illicit sinking of boreholes, mining and quarrying, spillage, toxic deposits, exploration and exploitation, etc. (e) urbanization and its associated effects on the environment.

Furthermore, excerpts from the perceptions of participants towards human impacts on environment were vividly described in the following expressions: "noise pollution in the rivalry and unhealthy competitions characteristic of spiritual jingoism among religious adherents and business-derive used to heat up noise pollution in the vicinity'; 'garbage and landfills - the civilian barrack or face me i face you-type of houses increases generation of garbage and refuse'; 'activities of some shylock landlords is responsible for environment problems'; 'shot-put is popular in civilian barracks'. On air pollution, expressions include: 'effumes from jalopy and rickety cars';' i better pass my neighbor generating sets'; 'activities of the chain smokers'. On water pollution expressions include: the 'search for bush meat'; 'corner-cutting for riches-bunkering', etc. The foregoing is an express description of the extent to which human beings have impacted on the environment. Findings here buttress previous studies on human impacts on the environments that recognize the prevalence of human activities and its impact on the environment (Kelvin \& Lewies, 1995; Jekayinoluwa, 2005; TSE (n.d); Gbadamosi, 2012; Ogundare, 2013; Oladiti, 2010).

With regards to the effects of human activities on the environment, content analysis and categorization of participants' views into convergent and divergent views were attempted. Content analyses of participants' view revealed enormous effects that human impacts on the environment are associated with. While there are consensus on such effects on human beings and the components of environment generally, there were divergent views on the extent and recipients of such effects.

In concrete term, multiplier effects of human environmental impacts as expressed by participants constitute an unending dossier. Such effects are in terms of climate change and the associated global warming, weather fluctuations, rainfall emanating from depletion of ozone layer, land degradation and associated low agricultural output, raw materials and folding up of companies; land, air and water pollution, perennial food insecurity and its concomitant effects of malnutrition and scavenging, health related effects and associated 
disease and breakout of epidemics; resource depletion and loss of plants and animals; deforestation and desertification, extinction of species, reduction in life expectancy and associated high mortality rates, disruption of ecosystem and biodiversity coupled with reduction in foreign exchange earnings. Findings here are in consonance with some previous studies that have berated undue impacts of human beings on the environment and resultant over-stretching of the earth's carrying capacity (Environmental Education Training Manual, 2007; Gbadamosi, 2012; Adekunle 2005; TSE, n.d; Kelvin \& Lewies, 1995; Ogundare, 2013). However, some participants were of the view that some of the impacts are like double- edged sword to the environment.

Be that as it may, the study revealed the desirability of responsible attitude towards the environment. The following excerpts are culled from participants' disposition towards environment vis-à-vis human impact: 'environment is our life wire, we can't afford to toy with it'; 'I feel the task of protecting environment should be a cooperative one'; 'the issue of environment and man is like the analogy of lice and dog'; 'for some people, it is business as usual whenever it rains by dumping refuse in the gutters'; 'human beings are only destroying environment to their own peril'; 'government should do more to protect environment'; 'if there is no environment, we can't survive, the onerous task is humans'; 'if we play safe with environment, we will reduce environmental challenges'. The foregoing is an indication of readiness to take responsibility on the environment. Findings here corroborate some previous studies that underscored rational attitude as bedrock of responsible attitudes to environment and sustainable environment at large (UNESCO, 2008; Gbadamosi, 2012; Feinberg \& Willer, 2012; Schwartz, 1977; Kelvin \& Lewies, 1995, Adedoyin, 2014; Oladiti, 2007; Stern, Dietz, Abel, Guagnano and Kalof, 1999).

\section{CONCLUSION}

In as much as the bedrock of human continuous existence and survival are imbued in the environment, the quality as well as environmental sustainability cannot be overemphasized. Going by the spate of human actions and inactions in terms of activities on the environment, a lot has been done that has resulted in the alteration of the carrying capacity of the environment. Continuous and unabated nature of human impacts on the environment therefore is a threat to the environment the endangered species and the associated biodiversity and ecosystem. Surmounting the multiplier effects of human activities on the cosmos therefore calls for concerns on the part of stakeholders on environment. Thus, individuals, organizations as well as government at national and international levels have enormous role to play in ensuring environmental sustainability.

This becomes pertinent both for the present and to avoid jeopardizing the generations yet unborn. Consequently, development of rational attitude to the environment will go a long way in salvaging the environment from its degraded state arising from human deleterious actions. Hence, the task of responsible attitude to the environment is a requisite for sustainable environment and sustainable development. 


\section{References}

[1] Adedoyin A. (April 2014). Emergency volunteering to the rescue. National Mirror p. 54.

[2] Adekunle M. O., Journal of Arts and Social Sciences 1(1) (2006).

[3] Adekunle M. O. (2005). Problem-solving and concept-mapping strategies as determinants of students' achievement and attitudes in some environmental concepts in Social Studies. Unpublished Ph.D Thesis, Department of Teacher Education, University of Ibadan, Ibadan.

[4] Agunbiade A. O. (2007). The impact of structural adjustment programme (SAP) on the Nigerian Environment in Okali, D; Ologe, K.O. \& Igbozurike, U.M. (Eds.) Perspectives in environmental management. Ibadan: NEST.

[5] Ajiboye J.O., Oyetade E.M., Nigerian journal of Social Studies VIII(1\&2) (2005).

[6] Akinkuotu A. (November 2012). Putting the classroom before the work place. Tell Magazine 12, November p. 68.

[7] Benedict H. T., Nigeria journal of Social Studies VIII(1\&2) (2005).

[8] Chen X., Pillutla M. M., Yao X., Group process \& intergroup relations 12 (2009) 241-255.

[9] Dunlap R.E., Xiao C., McRight A. M., Environment Politic 10 (2001) 2348.

[10] Environmental Education Training (2007). Environmental Education training manual. Retrieved on $15^{\text {th }}$ September, 2009 from htty://www.ericdigest/training.

[11] Feingberg M., Willer R. (2012). The moral roots of environmental attitudes. Center for compassion and altruism research and education, Stanford university, Stanford.

[12] Feygina I., Jost J.T., Godsmisth R.E., Personality and Social Psychological Bulletin 36 (2010) 326-338.

[13] Gbadamosi T. V. 2012. Effects of service learning and educational trips instructional strategies on primary school pupils' environmental literacy in Social Studies, Oyo State, Nigeria. A dissertation in the Department of Teacher Education, Faculty of Education, University of Ibadan, Ibadan.

[14] Jekayinoluwa J. R., Nigerian journal of Social Studies VIII(1\&2) (2005).

[15] Kerin T. P., Lewies A. O. (1995). An introduction to global issues. London, Routledge publishers.

[16] Lakoff G. (1996). Moral politics: what conservatives know that liberals don't. Chicago, IL: University of Chicago press.

[17] Mcright A. M., Dunlap R. E., The Sociological Quarterly 52 (2011) 155-194.

[18] Meyer C. (2003). Editorial, the magazine of future welfare, File : a: / July 2003. http.

[19] Mordi R. (October 2012). Nigeria at 52: up on the insecurity index. Tell Magazine 8 October, p. 50.

[20] Nwankiti O. C. (1983). Man and his environment, Lagos, Longman Nigeria, Vol. 42(1). 
[21] Ogundare I. O. (2013). Inclusion of climate change issues in Nigerian secondary school curriculum-the raison d'etre. Paper presented at the $26^{\text {th }}$ annual conference of Curriculum Organization of Nigeria held at University of Port Harcourt, Port Harcourt, Nigeria between $18 \& 21$ September.

[22] Oladiti A. A., Wahab E. I., Nigeria journal of Social Studies XVI(2) (2013).

[23] Oladiti A. A., Ayanwale O., Journal of Social Studies X(1\&2) (2007).

[24] Oladiti A. A. (2010). Man and his physical environment. Ibadan, Isegun publishing company.

[25] Raymond M. (2012). Any hope for the Nigerian child? Tell magazine, No. 22, June 4.

[26] Schwartz S. H. (1977). Normative influences on altruism .in L.Bekowitz (Ed.) Advances in experimental social psychology 10, pp. 221-279. New York, NY: academic press.

[27] Stern P. C., Dietz T., Abel T., Guagnano G.A., Kalof L., Human Ecology Review 6 (1999) 81-97.

[28] UNESCO 2008. Education for sustainable development. Retrieved $10^{\text {th }}$ octomber, 2009 From: httywww.esdtoolkit.org/discussion. 